\title{
UPAYA PENINGKATAN KUALITAS PAUD PUTIH MELATI KELURAHAN MERGOSONO KECAMATAN KEDUNGKANDANG MALANG MELALUI PENDIDIKAN ANAK USIA DINI DAN PENINGKATAN KUALITAS PENDIDIK
}

\author{
Nilawati F., Baroroh L., Farika N., Achmad Z., Yosi A. \\ barorohlestari@gmail.com
}

\begin{abstract}
Abstrak - In Indonesia, the age between 0-6 years is agreed, which is explained in article 28 of the Law on the National Education System no. 20 of 2003 paragraph 1 explained that "early childhood is a child who falls in the age range of 0-6 years". Thus it can be stated that early childhood is a child in the range of 0-6 years who have growth and development according to their characteristics. In Mergosono Sub-District, Kedungkandang District, there are 6 (six) Pos PAUD. Pos PAUD Putih Melati is one of the Pos PAUD located in RW 1, Mergosono Sub-District, Kedungkandang District. This Pos PAUD was created with the aim of meeting the needs of the surrounding community, especially with regard to early childhood education. So far, Pos PAUD have been managed more based on principles from, by and for the community. The method used in this PkM is the transfer of knowledge and discussion of problems. The implementation of activities in the form of management training and financial administration of Pos PAUD, procurement of Educational Game Equipment (APE), procurement of APE storage lockers, and procurement of Pos PAUD financial administration books. Financial Management and Administration Training for the managers of Pos PAUD Putih Melati was the result of the initial discussion. Based on the results of the discussion it was found that the Pos PAUD Putih Melati manager experienced obstacles in terms of financial management and administration. Therefore, dedication was carried out in the form of providing material related to the management and financial administration of Pos PAUD Putih Melati. Overall, the service activities carried out at the Pos PAUD Putih Melati can be said to be successful. This success is not only measured by the four components above, it can also be seen from the participants' satisfaction after participating in the activities and the use of APE by students of the Pos PAUD Putih Melati. Based on the results of the implementation of the dedication that has been carried out, several suggestions can be submitted, namely: 1) The time of the implementation of the service activities needs to be increased so that the objectives of the activity can be fully achieved. 2) The existence of follow-up activities in the form of similar training is always held periodically so as to improve the ability of teachers to carry out the teaching and learning process.
\end{abstract}

Kata kunci: Pos PAUD, APE, children's motoric, teacher, Puth Melati

\section{PENDAHULUAN}

\subsection{Latar Belakang}

Di Indonesia usia dini disepakati usia antara 0-6 tahun yang dijelaskan pada pasal 28 Undang-Undang Sistem Pendidikan Nasional no. 20 tahun 2003 ayat 1 dijelaskan bahwa "anak usia dini adalah anak yang masuk dalam rentang usia 0-6 tahun". Dengan demikian dapat dikemukakan bahwa anak usia dini adalah anak yang berkisar antara 0-6 tahun yang memiliki pertumbuhan dan perkembangan sesuai dengan karakteristiknya. Pendidikan anak usia dini (PAUD) merupakan upaya yang dilakukan dalam menciptakan tunas-tunas bangsa yang berkualitas serta siap untuk bersaing dalam arus perkembangan jaman. Pendidikan anak usia dini merupakan investasi yang sangat berharga bagi bangsa, karena anak-anak usia dini merupakan generasi penerus bangsa. Disebutkan dalam Undang-undang Republik Indonesia No. 23 tahun 2003 tentang Sistem Pendidikan Nasional, pasal 1, ayat 14 (Depdiknas, 2008b:1) bahwa :

Pendidikan anak usia dini merupakan upaya pembinaan yang ditujukan kapada anak sejak ia lahir sampai dengan usia enam tahun yang dilakukan melalui pemberian rangsangan pendidikan untuk membantu pertumbuhan dan perkembangan jasmani dan rohani anak, agar memiliki kesiapan dalam memasuki pendidikan lebih lanjut.

Pendidikan anak usia dini merupakan salah satu bentuk penyelenggaraan pendidikan yang menitikberatkan pada peletakan dasar ke arah pertumbuhan dan perkembangan fisik (koordinasi motorik halus dan kasar), kecerdasan (daya pikir, daya cipta, kecerdasan emosi, kecerdasan spiritual), social emosional (sikap dan perilaku serta beragama), bahasa dan komunikasi sesuai dengan keunikan tahap-tahap perkembangan yang dilalui oleh anak usia dini.

Tingkat pendidikan Tutor PAUD bervariasi, terdapat disparitas/kesenjangan tingkat pendidikan yang seharusnya dipenuhi oleh seorang pendidik PAUD profesional. Mengacu pada PP No. 19/2005 Tentang Standar Nasional Pendidikan pada pasal 28 dan 29 dinyatakan bahwa pendidik anak usia dini harus memiliki kualifikasi akademik dan kompetensi yang memadai sebagai agen pembelajar. Kualifikasi akademik yang harus dipenuhi oleh pendidik AUD yakni berpendidikan minimum diploma empat (D-IV) atau sarjana (S1). Persyaratan lain antara lain berlatar belakang pendidikan tinggi di bidang pendidikan anak 
usia dini, kependidikan lain, atau psikologi; dan memiliki sertifikat profesi guru untuk PAUD. Kompetensi Pendidik PAUD yang harus dipenuhi meliputi : (a) kompetensi pedagogik, (b) kompetensi kepribadian, (c) kompetensi profesional, (d) kompetensi sosial.

Di Kelurahan Mergosono Kecamatan Kedungkandang, terdapat 6 (enam) Pos PAUD. Pos PAUD Putih Melati merupakan salah satu Pos PAUD yang terdapat di RW 1 Kelurahan Mergosono Kecamatan Kedungkandang. Pos PAUD ini dibuat dengan tujuan untuk memenuhi kebutuhan masyarakat sekitar terutama berkaitan dengan pendidikan anak usia dini. Selama ini Pos PAUD lebih banyak dikelola berdasarkan prinsip dari, oleh dan untuk masyarakat.

Hasil identifikasi terhadap khalayak sasaran ternyata Pos PAUD Putih Melati, permasalahan yang dihadapi adalah oleh Pos PAUD Putih Melati adalah guru-guru yang bekerja di sana, belum memenuhi kualifikasi akademik dan kompetensi sebagaimana diamanatkan dalam Peraturan Pemerintah tersebut. Pengalaman mengajar guru PAUD yang memiliki kualifikasi akademik SMA/Sederajat pada umumnya sudah mengajar diatas empat tahun. Selain itu, pengalaman pelatihan terkait pengelolaan Pos PAUD masih sangat minim. Kualifikasi akademik, pengalaman mengajar, pengalaman pelatihan yang relevan serta kompetensi yang tidak memadai berpengaruh terhadap kualitas pembelajaran yang diselenggarakan oleh tutor PAUD tersebut. Disamping kualitas pengajar, Pos PAUD Putih Melati juga mengalami masalah dengan pengadaan Alat Permainan Edukatif (APE) dan rak tempat menyimpan APE tersebut. Pos PAUD tersebut sudah memiliki APE, tetapi masih minim.

\section{KAJIAN TEORI}

\subsection{Pengertian PAUD}

Ditinjau dari segi usia, anak usia dini adalah anak yang berada dalam rentang usia 0-8 tahun (Morrison, 1989). Standar usia ini adalah acuan yang digunakan oleh NAEYC (National Assosiation Education for Young Child). Menurut definisi ini anak usia dini merupakan kelompok yang sedang berada dalam proses pertumbuhan dan perkembangan. Hal ini mengisyaratkan bahwa anak usia dini adalah individu unik yang memiliki pola pertumbuhan dan perkembangan dalam aspek fisik, kognitif, sosioemosional, kreativitas, bahasa dan komunikasi yang khusus sesuai dengan tahapan yang sedang dilalui oleh anak tersebut. Anak usia dini terbagi menjadi 4 (empat) tahapan yaitu masa bayi dari usia lahir sampai 12 (dua belas) bulan, masa kanakkanak/batita dari usia 1 sampai 3 tahun, masa prasekolah dari usia 3 sampai 5 tahun dan masa sekolah dasar dari usia 6 sampai 8 tahun. Pada setiap tahapan usia yang dilaluinya anak akan menunjukkan karakteristiknya masing-masing yang berbeda antara tahap yang satu dengan tahap yang lainnya. Oleh karenanya, proses pendidikan sebagai bentuk perlakuan yang diberikan pada anak usia dini haruslah memperhatikan karakteristik yang dimiliki setiap tahapan perkembangan.

\subsection{Pendekatan dalam Pendidikan Anak Usia Dini}

Pembelajaran anak usia dini pada dasarnya menganut pendekatan bermain sambil belajar atau belajar sambil bermain. Sesuai dengan karakteristik anak yang bersifat aktif dan eksploratif terhadap lingkungannya. Anak belajar dengan caranya sendiri. Ada beberapa pendekatan dalam pembelajaran pada anak usia dini, yaitu :

- Berorientasi pada kebutuhan anak

- Berorientasi pada perkembangan anak

- Belajar melalui bermain

- Pembelajaran Aktif, Kreatif, Efektif, dan Menyenangkan

- Stimulasi dan Pembelajaran Terpadu

\subsection{Lingkup Perkembangan Motorik Anak}

Lingkup perkembangan pada anak usia dini terdiri dari lima lingkup, yaitu nilai agama dan moral, fisik motorik, kognitif, sosial emosional dan bahasa hal tersebut dapat dilihat pada Permendikas Nomor 58 (2009) dan juga pada Kurikulum 2013 (2013). Begitu pula dijelaskan oleh Suyadi (2013) bahwa kecerdasan pada anak bukan hanya pada otaknya yang berkembang cepat tetapi bergantung pada pertumbuhan dan perkembangan pada aspek yang lain, aspek tersebut ditentukan oleh tingkat pencapaian perkembangan, aspek yang dimaksud adalah fisik motorik, bahasa, kognitif, sosial-emosional dan rasa beragama. Maka dari itu dapat disimpulkan bahwa lingkup perkembangan pada anak ada lima, yaitu fisik motorik, bahasa, kognitif, sosial emosional dan rasa beragama.

\subsection{Manajemen}

Manajemen secara etimologi berasal dari bahasa inggris management yang dikembangkan dari kata to manage, yang artinya mengatur atau mengelola. Kata manage ini sendiri berasal dari Italia Maneggio yang diadopsi dari bahasa latin managiare, yang berasal dari kata manus yang artinya tangan (Tim Dosen Administrasi Pendidikan UPI, 2011:230). Sedangkan dalam kamus besar bahasa Indonesia kata manajemen mempunyai pengertian sebagai penggunaan sumberdaya secara efektif untuk mencapai sasaran (Yuku, 2013:29). Dalam arti khusus manajemen dipakai bagi pemimpin dan kepemimpinan yaitu orang-orang yang melakukan kegiatan memimpin dalam suatu organisasi. Manajemen cenderung dikatakan sebagai ilmu maksudnya seseorang yang belajar manajemen tidak pasti akan menjadi seorang menejer yang baik.

Fungsi-fungsi Manajemen menurut Siagian mencakup:

- Perencanaan (planning) dapat didefenisikan sebagai keseluruhan proses pemikiran dan penentuan secara 
matang tentang hal-hal yang akan dikerjakan dimasa yang akan datang dalam rangka mencapai tujuan yang telah ditetapkan.

- Pengorganisasian (Organizing) adalah keseluruhan proses pengelompokan orang-orang, alat-alat, tugas-tugas, tanggung jawab dan wewenang sedemikian rupa sehingga menciptakan suatu organisasi yang dapat digerakkan sebagai suatu kesatuan dalam rangka pencapaian tujuan yang telah di tentukan.

- Penggerakan (Motivating) dapat didefenisikan sebagai keseluruhan proses pemberian dorongan bekerja kepada para bawahan sedemikian rupa sehingga mereka mau bekerja dengan ikhlas demi tercapainya tujuan organisasi dengan efesien dan ekonomis.

- Pengawasan (Controlling) adalah proses pengamatan pelaknsanaan seluruh kegiatan organisasi untuk menjamin agar semua pekerjaan yang sedang dilakukan berjalan sesuai dengan rencana yang telah ditentukan sebelumnya.

- Penilaiyan (Evaluation) adalah fungsi organik administrasi dan manajemen yang terakhir. Defenisinya ialah proses pengukuran dan perbandingan hasil hasil pekerjaan yang nyatanya dicapai dengan hasil-hasil yang seharusnya dicapai.

\section{METODE}

Sasaran dalam kegiatan Pengabdian Kepada Masyarakat (PkM) ini adalah Pos PAUD Putih Melati Kelurahan Mergosono Kecamatan Kedungkandang Malang. adalah:

Metode yang digunakan dalam kegiatan PkM ini

- Alih Pengetahuan

- Alih pengetahuan diberikan dengan metode penyampaian materi yang sesuai dengan bimbingan yang dilaksanakan serta dengan memberikan contoh-contoh dalam bentuk slide mengenai pengelolaan manajemen Pos PAUD dan pemilihan APE yang terstandart untuk meningkatkan kualitas motorik anak didik Pos PAUD Putih Melati.

- Pembahasan Masalah

- Dalam kegiatan ini pelaksana PkM terlibat secara langsung membantu guru dan manajemen Pos PAUD Putih Melati dalam mengelola Pos PAUD menggunakan pendekatan $P O A C$ dalam teknik menyampaikan materi penggunaan Pendekatan $P O A C$ untuk mengelola Pos PAUD, menjaga situasi tetap formal, pemilihan bahasa yang tegas, lugas tapi sopan, terutama bagaimana cara mempengaruhi guru dan manajemen Pos PAUD Putih Melati namun tidak terkesan menggurui.
Sesuai dengan metode PKM yang dirancang pada Bab IV, maka pelaksanaan kegiatan pengabdian sebagai berikut:

- Pelatihan Manajemen dan Administrasi Keuangan Pos PAUD Putih Melati

- Berdasarkan hasil wawancara awal dengan pengelola Pos PAUD Putih Melati, maka diperoleh informasi bahwa pihak pengelola mengalami kesulitan dalam melakukan manajemen dan administrasi keuangan Pos PAUD Putih Melati. Pelatihan yang diberikan disini berkaitan dengan manajemen keuangan penyelenggara Pos Pos PAUD Putih Melati yang meliputi penyusunan RAPBS, pengelolaan keuangan sekolah yang efektif, pengelolaan anggaran sekolah, dan pertanggung jawaban keuangan sekolah.

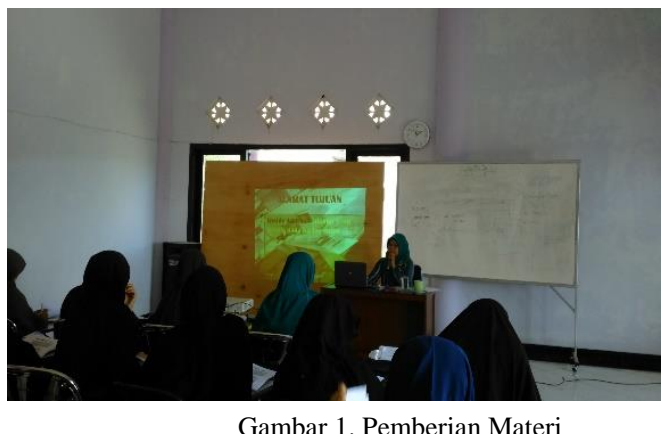

- Pengadaan Alat Permainan Edukatif (APE)

Pengadaan APE berupa alat-alat peraga yang berkaitan dengan angka, huruf, alat musik, kendaraan dan binatang. Dengan demikian, diharapkan peserta didik Pos PAUD Putih Melati dapat mengidentifikasi dan mengenai hal-hal yang berkaitan dengan angka, huruf, alat musik, jenisjenis kendaraan dan jenis-jenis binatang. Kemudian juga berupa puzzle yang akan mengasah kemampuan motorik anak.

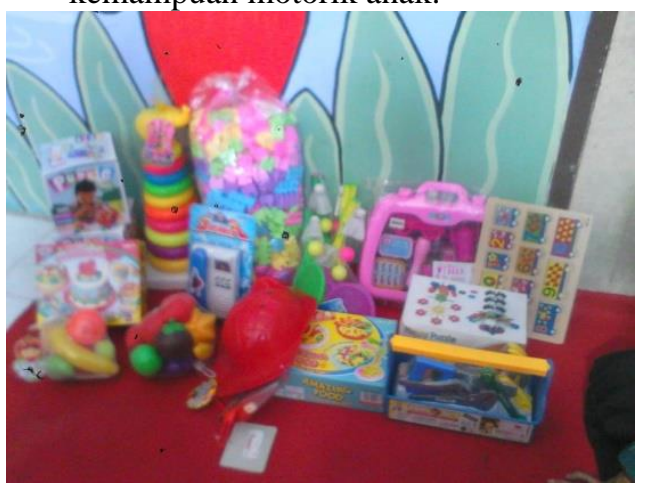

Gambar 2. Pemberian APE 1

\section{HASIL DAN PEMBAHASAN}

\subsection{Pelaksanaan Kegiatan}




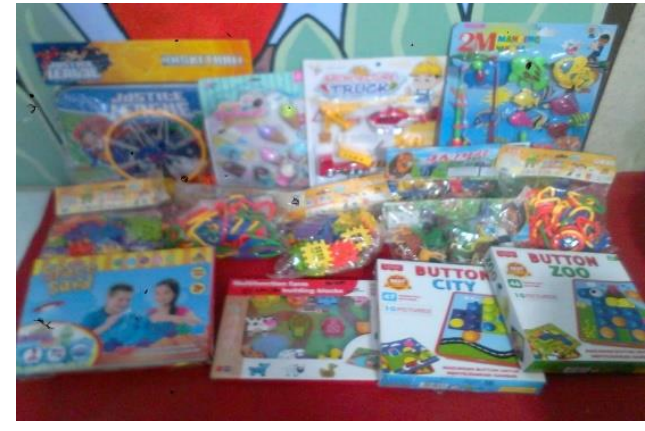

Gambar 3. Pemberian APE 2

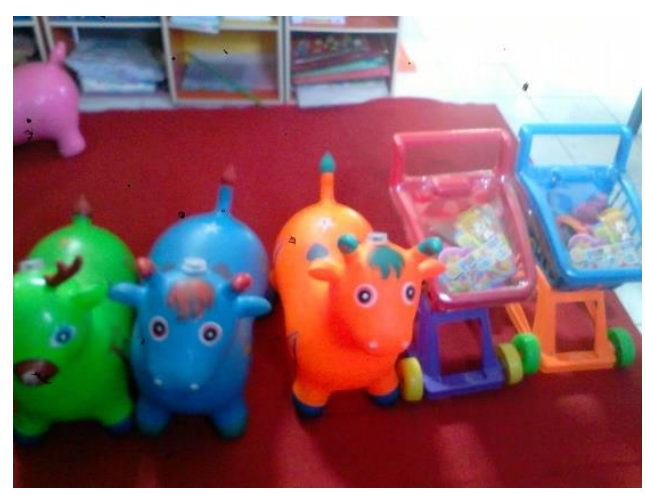

Gambar 4. Pemberian APE 3

- Pengadaan loker untuk penyimpanan APE.

Pengadaan loker penyimpanan bertujuan untuk sarana penyimpanan APE yang telah diberikan. Dengan demikian, APE dapat mudah diambil dan dirapikan kembali oleh peserta didik Pos PAUD Putih Melati.

- Pengadaan Buku Administrasi Pos PAUD Pengadaan buku administrasi Pos PAUD ini bertujuan untuk membantu Pos PAUD Putih Melati dalam melakukan tertib administrasi. Mulai dari pencatatan surat masuk dan surat keluar. Pencatatan keuangan. Pencatatan yang berkaitan dengan personalia Pos PAUD Putih Melati.

\subsection{Pembahasan}

Pelatihan Manajemen dan Administrasi Keuangan bagi pengelola Pos PAUD Putih Melati merupakan hasil dari diskusi awal. Berdasarkan hasil diskusi diketahui bahwa pengelola Pos PAUD Putih Melati mengalami kendala dalam hal manajemen dan administrasi keuangan. Oleh karena itu, dilakukan pengabdian dalam bentuk pemberian materi berkaitan dengan manajemen dan administrasi keuangan Pos PAUD Putih Melati.

Target peserta pelatihan manajemen dan administrasi keuangan pengelolaan Pos Pos PAUD adalah pengelola Pos PAUD Putih Melati. Dalam kegiatan ini, seluruh pengelola dapat hadir dan mengikuti kegiatan tersebut dengan baik. Materi yang disampaikan meliputi penyusunan RAPBS, pengelolaan keuangan sekolah yang efektif, pengelolaan anggaran sekolah, dan pertanggung jawaban keuangan sekolah. Ketercapaian tujuan pelatihan manajemen dan administrasi keuangan pengelolaan Pos Pos PAUD serta penyediaan APE dan lemari penyimpanan APE telah tercapai dengan baik.

Ketercapaian target materi pada kegiatan pengabdian ini cukup baik, karena materi pendampingan telah dapat disampaikan secara keseluruhan. Materi yang disampaikan antara lain: penyusunan RAPBS, pengelolaan keuangan sekolah yang efektif, pengelolaan anggaran sekolah, dan pertanggung jawaban keuangan sekolah.

Kemampuan peserta dalam penguasaan materi masih kurang dikarenakan waktu yang singkat dalam penyampaian materi dan kemampuan para peserta yang berbeda-beda. Hal ini disebabkan jumlah materi yang banyak hanya disampaikan dalam waktu sehari sehingga tidak cukup waktu bagi para peserta untuk memahami dan mempraktekkan secara lengkap semua materi yang diberikan.

Secara keseluruhan kegiatan pengabdian yang dilakukan di Pos PAUD Putih Melati dapat dikatakan berhasil. Keberhasilan ini selain diukur dari keempat komponen di atas, juga dapat dilihat dari kepuasan peserta setelah mengikuti kegiatan dan penggunaan APE oleh peserta didik Pos PAUD Putih Melati.

\subsection{Luaran yang dicapai}

Luaran dalam kegiatan pengabdian ini adalah: Artikel yang dipublikasikan di Jurnal ilmiah ber-ISSN.

\section{SIMPULAN DAN SARAN}

\subsection{Simpulan}

Kegiatan ini bertujuan untuk meningkatkan kualitas Pos PAUD Putih Melati dalam meningkatkan kualitas motorik anak dan kualitas pengelola Pos PAUD Putih Melati. Dengan demikian, diharapkan anak akan semakin meningkat perkembangan kognitifnya, Kegiatan yang sudah dilakukan di Program Pengabdian Masyarakat ini berupa peningkatan peralatan permainan edukatif berupa alat peraga edukatif (APE) yang bersifat indoor dan dilengkapi dengan loker untuk penyimpanan APE. Sementara untuk meningkatkan pengetahuan dan ketrampilan guru-guru Pos PAUD Putih Melati dilakukan pelatihan mengenai manajemen dan administrasi Pos PAUD.

\subsection{Saran}

Berdasarkan hasil pelaksanaan pengabdian yang telah dilakukan dapat diajukan beberapa saran sebagai berikut:

- Waktu pelaksanaan kegiatan pengabdian perlu ditambah agar tujuan kegiatan dapat tercapai sepenuhnya.

- Adanya kegiatan lanjutan yang berupa pelatihan sejenis selalu diselenggarakan secara periodik sehinga dapat meningkatkan kemampuan guru dalam melaksanakan proses belajar mengajar. 


\section{DAFTAR REFERENSI}

[1]. Departemen Pendidikan Nasional. (2009). Permen 58 tahun 2009. Jakarta: Direktorat Jendral Mnajemen Pendidikan Dasar dan Menengah Pembinaan TK SD.

[2]. Departemen Pendidikan Nasional. (2013). Kurikulum 2013. Jakarta: Direktorat Jendral Manajemen Pendidikan Dasar dan Menengah Pembinaan TK SD.

[3]. Departemen Pendidikan Nasional. (2000). Situasi dan Kondisi Perawatan dan Pendidikan Anak Dini Usia. Jakarta: Depdiknas.

[4]. Direktorat Pendidikan Anak Usia Dini. (2002). Naskah Akademik Pendidikan Anak Dini Usia. Jakarta: Depdiknas.

[5]. Direktorat Pendidikan Anak Usia Dini. (2003). Buletin PADU. Jakarta: Depdiknas.

[6]. Direktorat Pendidikan Anak Usia Dini (2004). Buletin PADU. Jakarta: Depdiknas.

[7]. Direktorat Pendidikan Anak Usia Dini. (2005). Buletin PADU. Jakarta: Depdiknas.

[8]. Direktorat Pendidikan Anak Usia Dini. (2006). Buletin PADU. Jakarta: Depdiknas.

[9]. Departemen Pendidikan Nasional. Rencana Aksi Nasional Pendidikan Untuk Semua 2003 - 2015. Jakarta: Depdiknas.

[10]. Direktorat Pendidikan Anak Usia Dini. (2005). Rencana Strategis (Renstra) Direktorat Pendidikan Anak Usia Dini 2005 - 2009. Jakarta: Depdiknas.

[11]. Direktorat Pendidikan Anak Usia Dini. (2007). Grand Desain Pendidikan Anak Usia Dini tahun 2007. Jakarta: Depdiknas.

[12]. Direktorat Jenderal Pendidikan Luar Sekolah. (2006). Pedoman Teknis Penyelenggaraan Kelompok Bermain. Yogyakarta: Departemen Pendidikan Nasional.

[13]. Direktorat Jenderal Pendidikan Anak Usia Dini dan Pendidikan Masyarakat. (2015). Jumlah Satuan PAUD D.I.Yogyakarta.. Diunduh pada app.pauddikmas.kemendikbud.go.id/pendataan/dap odikpaudni/index.php?md=reporttp\&item=report_0 1a\&propid=34\&kbkot_id=3471\&kec_id=kel_id=. Jumlah Satuan PAUD D.I.Yogyakarta. Jakarta: Kementrian Pendidikan dan Kebudayaan Indonesia. 23 Februari 2018. 10.00

[14]. Hasan, Maimunah. (2012). Pendidikan Anak Usia Dini. Yogyakarta: DIVA Press.

[15]. Handoko, T. Hani (1995), Manajemen Personalia dan Sumberdaya Manusia, Yogyakarta: BPFE.

[16].Suyadi. (2010). Psikologi Belajar Pendidikan Anak Usia Dini. Yogyakarta: Pedagogia.

[17].Muhammad Fadlillah. (2012). Desain Pembelajaran PAUD. Yogyakarta: ArRuzz Media.
[18].Hasan, Maimunah (2010) PAUD (Pendidikan Anak Usia Dini): Panduan Lengkap Manajemen Mutu Pendidikan Anak Untuk Para Guru Dan Orang Tua, Diva Press, Yogyakarta.

[19]. Rita Eka, Siti Partini, Yulia Ayriza, Hiryanto, Rosita. (2008). Perkembangan Peserta Didik. Yogyakarta: UNY Press.

[20].Pimpinan Pusat HIMPAUDI Indonesia. (2007). Pedoman Kerja Himpunan Pendidik dan Tenaga Kependidikan Anak Usia Dini (HIMPAUDI) tahun 2007.

[21].Suyadi, Konsep Dasar Paud, Rosdakarya, Bandung, cet. I, 2013. 